\title{
A Case of Classical Galactosaemia presenting with Fanconi syndrome
}

\author{
Imalke Kankananarachchi ${ }^{1}$, Thilina Madushanka Munasinghe ${ }^{2}$, Chamidri Naotunna ${ }^{2}$,Harshini Dharmawardena ${ }^{2}$, Gemunu
}

Hewawitharana ${ }^{2}$, Navoda Atapattu ${ }^{3}$, Sujeewa Amarasena ${ }^{1}$

${ }^{1}$ Faculty of Medicine, University of Ruhuna ${ }^{2}$ Teaching Hospital Karapitiya ${ }^{3}$ Lady Ridgeway Hospital

\section{Abstract}

Galactosaemia is a rare autosomal recessive metabolic disorder with the prevalence of 1;60000. Classical Galactosaemia (CG) is the most common variant of Galactosaemia and which is due to deficiency of Galactose-1-phosphate Uridyltransferace enzyme. Fanconi Syndrome (FS) is a rare presentation of CG. Here we present a baby girl with CG presenting with FS, which led to a diagnostic difficulty.

Copyright: This is an open-access article distributed under the terms of the Creative Commons Attribution License, which permits unrestricted use, distribution, and reproduction in any medium, provided the original author and source are credited (CC BY 4.0)

iD https://orcid.org/0000-0002-9351-2966

\section{Introduction}

Galactosaemia is a rare autosomal recessive metabolic disorder with the prevalence of $1 ; 60000$ (1). Classical Galactosaemia (CG), Galactokinase deficiency and Galactose Epimerase deficiency are the different types of Galactosaemia (2). In CG, there is a deficiency of Galactose1-phosphate Uridyltransferace (GALT) enzyme (1). Fanconi Syndrome (FS) or proximal renal tubular dysfunction is a rare association of CG (2). Here we present a baby girl with CG presenting with FS.

\section{Case Report}

A 5-month old baby girl presented with recurrent vomiting since early neonatal period. She was the first baby born to second degree consanguineous parents following uncomplicated antenatal period, with a birth weight of $2.35 \mathrm{~kg}$. She was commenced on breast feeding within one hour of birth and discharged on day 3. The baby had unconjugated hyperbilirubinaemia since day 2 onwards and has received double phototherapy during the post-natal ward stay.

She was exclusively breast fed and there was a history of non-bilious vomiting following feeds since early neonatal period. There was no history of prolonged jaundice, pale stools or dark urine. Her weight gain was suboptimal and there was a global developmental delay.
On admission, she looked ill, tachypnoeic and dehydrated. There was no pallor or icterus. Her weight and length were $4.4 \mathrm{~kg}(<-3 \mathrm{SD})$ and $55 \mathrm{~cm}(<-3 \mathrm{SD})$ respectively. There was $4 \mathrm{~cm}$ hepatomegaly without splenomegaly. Her development age was 3 months. Rest of her physical examination was normal.

Her basic haematological parameters and inflammatory markers were normal. There were elevated liver enzymes with normal renal functions. She had normal anion gap metabolic acidosis and her both clinitest and clinistix tests were positive. Further investigations revealed proximal tubular dysfunction (Table 1). Her bone profile showed hypophosphataemia, hypocalcaemia and low vitamin D3 levels. Ophthalmological assessment didn't show cataract. Dry blood spot for serum galactose level was well above the normal range. $(67.55 \mathrm{mg} / \mathrm{dL})$.

Based on the clinical and biochemical findings, the diagnosis of CG complicated with FS was made and she was commenced on lactose free formula. For renal tubular acidosis, she was started on bicarbonate and potassium supplementation. Her symptoms were markedly improved with the treatment and subsequently there was a good weight gain. 


\begin{tabular}{l|cc} 
Investigation & Results & Reference range \\
\hline PH & 7.15 & $7.35-7.45$ \\
HCO3 (mmol/l) & 14 & $22-26$ \\
Serum Sodium $(\mathrm{mmol} / \mathrm{l})$ & 134 & $135-145$ \\
Serum Potassium $(\mathrm{mmol} / \mathrm{l})$ & 4.1 & $3.5-5.5$ \\
Serum Chloride $(\mathrm{mmol} / \mathrm{l})$ & 110 & $96-106$ \\
ALT $(\mathrm{U} / \mathrm{L})$ & 56 & $0-31$ \\
AST $(\mathrm{U} / \mathrm{L})$ & 218 & $0-34$ \\
Serum Bilirubin $(\mu \mathrm{mol} / \mathrm{L})$ & 13 & $5-21$ \\
Serum Albumin $(\mathrm{mg} / \mathrm{dl})$ & 35 & $35-53$ \\
Urine Protein creatinine ratio $(\mathrm{mg} / \mathrm{mmol})$ & 8.0 & $<3.0$ \\
Fractional renal tubular absorption of PO4 & 0.77 & $>0.85$ \\
Urine PH & 6.0 & $<5.5$
\end{tabular}

\section{Discussion}

CG is the most common variant of Galactosaemia (3). In developed countries, Galactosaemia is diagnosed during neonatal period as a result of newborn screening programmes. However, in Sri Lanka, there is no screening programme to detect Galactosaemia.

In GALT deficiency, there is a failure of conversion of Galactose 1 phosphate to Glucose 1 phosphate and UDP galactose to UDP glucose resulting excess accumulation of galactose in the body. Excess amount of galactose damages the major organs such as brain, kidney, liver and eyes (3).

Clinical features of CG include vomiting, failure to thrive, feeding difficulties, prolonged jaundice, hepatomegaly, hypotonia and cataract (2). In this case, except for cholestatic jaundice and cataract most of the other clinical features were there.

FS is a rare complication of CG and the presence of FS in CG might challenge the diagnosis of the underlying condition. In this case, the child had normal anion gap metabolic acidosis secondary proximal renal tubular dysfunction, however, CG alone would have presented with high anion gap metabolic acidosis (4). In addition, the characteristic investigation finding of Galactosemia is the positive urine reducing substances (Clinitest) in the absence of glycosuria (Clinistix) (3). However, when there is coexisting FS together with CG, both Clinitest and Clinistix would become positive challenging the diagnosis. The confirmatory test to diagnose CG is the erythrocyte GALT enzyme assay (5). In this child the test was not performed due to lack of facilities.

The mainstay of management of CG is the lifelong abstinence of lactose containing foods (5). In addition, associated complications such as liver failure, renal tubular dysfunctions and neurological manifestations needs to be addressed separately (5).

The prognosis of CG depends on the age at diagnosis. Those who were diagnosed through newborn screening programmes can have near normal life. However, they also can have mild degree of intellectual impairment and almost all females with CG develops primary ovarian failure (5).

\section{References}

1. Bosch AM. Classical galactosemia revisited. J Inherit Metab Dis. 2006; 29:-525. DOI: 10.1007/s10545-006-0382-0.

2. Santer R, Klepper J, Smit GP. Disorders of carbohydrate metabolism and glucose transport. In Physician's Guide to the Diagnosis, Treatment, and Follow-Up of Inherited Metabolic Diseases 2014 (pp. 265-301). Springer, Berlin, Heidelberg.

3. Berry GT, Segal S and Gitzelmann R. Disorders of Galactose Metabolism. Inborn Metabolic Diseases - Diagnosis and Treatment. 4. New York, NY: Springer-Verlag, Inc; 2006. https://doi.org/10.1007/978-3-540-28785-87

4. Haque SK, Ariceta G, Batlle D. Proximal renal tubular acidosis: a not so rare disorder of multiple etiologies. Nephrology Dialysis Transplantation. 2012 Dec 1; 27(12):4273-87. DOI: 10.1093/ndt/gfs493 
5. Jumbo-Lucioni PP, Garber K, Kiel J, Baric I, Berry GT, Bosch A, et al. Diversity of approaches to classic galactosaemia around the world: a comparison of diagnosis, intervention, and outcomes. J Inherit Metab Dis. 2012 Nov. 35(6):1037-49 DOI: $10.1007 /$ s10545-012-9477-y 